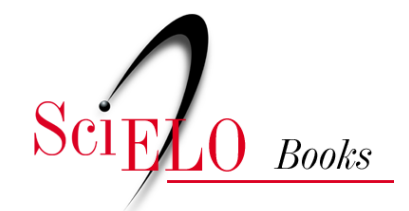

EDUFU

\title{
Jogo dramático segundo Jean-Pierre Ryngaert
}

\author{
Renan Tavares
}

\section{SciELO Books / SciELO Livros / SciELO Libros}

TAVARES, R. Jogo dramático segundo Jean-Pierre Ryngaert. In: FLORENTINO, A., and TELLES, N., eds. Cartografias do ensino do teatro [online]. Uberlândia: EDUFU, 2008, pp. 239-248. ISBN 978-85-7078-518-3. https://doi.org/10.7476/9788570785183.0025.

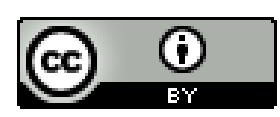

All the contents of this work, except where otherwise noted, is licensed under a Creative Commons Attribution 4.0 International license.

Todo o conteúdo deste trabalho, exceto quando houver ressalva, é publicado sob a licença Creative Commons Atribição $\underline{4.0}$.

Todo el contenido de esta obra, excepto donde se indique lo contrario, está bajo licencia de la licencia $\underline{\text { Creative Commons }}$ Reconocimento 4.0. 


\section{Jogo dRAmÁtico SEgundo JeAn-PierRe RyngaERT}

Só há idéias burguesas no que a escola da burguesia divulga. É burguês catapultar Victor Hugo em "pára-quedas" para crianças que ninguém preparou para acolher, é burguês interpretar Victor Hugo de maneira puramente formalista deixando na sombra as suas tomadas de posição essenciais: já não é burguês iniciar as crianças em Victor Hugo levando-as pouco a pouco a ir além do seu Tintin habitual. E é a melhor das oportunidades para que finalmente sejam eles próprios a extrair, quer dos seus livros, quer da sua experiência, aquilo que irá alimentar uma tomada de consciência criadora do mundo de hoje. (George Snyders)

A mudança, ou como diz Snyders, "a purificação revolucionária entre os contributos que a escola burguesa se compraz precisamente em amalgamar”, decorrerá de uma demanda de fora para dentro. É a convite dos alunos que a pedagogia do professor tenderá mais ou menos para a "escola progressista" que, no que diz respeito à arte, deve buscar "separar as exigências efetivamente fundadas da cultura e as mistificações, os disfarces a que essa mesma cultura dá lugar”.

Como relacionar a importância desta demanda dos alunos, sob a perspectiva de uma escola progressista, com a teoria e prática do jogo dramático de Jean-Pierre Ryngaert?

Seu primeiro livro, Le Jeu dramatique en milieu scolaire, datado de 1977, é portador de um capítulo exclusivo para definir o jogo dramático para o qual devemos dedicar uma leitura cuidadosa e investigativa. Em linhas gerais, o autor preocupa-se em delimitar as fronteiras entre o jogo dramático, o psicodrama e o teatro, ampliando largamente o universo teórico que até então enfocava o jogo dramático de forma generalizada, a partir de pressupostos que não lhe diziam respeito diretamente.

Neste artigo, vamos nos limitar a tratar desta definição em dois momentos distintos e entrelaçados no intuito não só de provocar a leitura da obra de Jean-Pierre Ryngaert, como também de proporcionar material para atividade de reflexão em sala de aula do Curso de Licenciatura/Formação de Professores em Artes 
Cênicas (Ensino do Teatro). No primeiro momento, nossa preocupação principal recairá sobre alguns aspectos que tratam da relação entre jogo dramático e teatro contemporâneo.

Ao afirmar que o jogo é um meio de conhecimento da realidade, Ryngaert não deixa de se questionar sobre que realidade se reproduz no jogo e que relações o jogo mantém com a arte - "um outro instrumento de modelização do mundo":

O jogo dramático deve ser simultaneamente um meio concreto de criação de situações e de aquisição de técnicas, e um meio de reflexão destas situações a fim de fazê-las tender para a invenção. É a coexistência do modelo abstrato e do modelo lúdico que permite avançar e escapar ao impasse que representa a reprodução de clichês ${ }^{1}$.

Sendo esta uma das abordagens mais importantes para definição do jogo dramático, importa deixá-la explicitada de forma que não se criem idéias falsas. Cabe também acrescentar que o que se tenta aqui não exclui a leitura do desenvolvimento integral dos argumentos selecionados pelo autor. A necessidade de abrir um debate por este enfoque reside no fato de encontrar na proposta de Ryngaert um deslocamento da preocupação com a expressão para aquela que recai sobre a comunicação. A relação entre a forma e o conteúdo, a importância que a Escola atribui ao significado, à sua compreensão, ao fato de tudo ser racionalmente entendido e explicado, adquire no jogo dramático uma particularidade:

É por isto que não colocamos a aquisição de uma técnica anterior à elaboração de um discurso. O fundo só poderia estar subordinado à forma ou só poderia visar a sua clarificação. A invenção de formas originais mais adaptadas a qualquer novo discurso é o objetivo determinante em direção do qual tendemos².

As mistificações e os disfarces, a que Snyders se refere, ora se realizam sob enfoque exclusivo da forma, ora sob enfoque exclusivo do conteúdo. Assim, "a pesquisa da expressão está estreitamente ligada às exigências do conteúdo, e o trabalho sobre a forma a uma crítica do conteúdo", explicita Ryngaert quando se refere diretamente ao que ele chama de comportamento lucidamente elaborado. O jogo dramático se dá sempre numa situação de comunicação, na medida em que busca a inventividade, o questionamento dos modelos culturais, a aproximação com a estética teatral. Um instrumento que, desta maneira, evita as armadilhas da imitação estéril. "É por isto que se torna não somente um instrumento de análise do mundo, mas também uma arma diante do mundo"3.

A improvisação tem, assim, de se preocupar lucidamente com as formas que serão convocadas para explicitar a situação que se quer mostrar aos observadores. São estes que vão retornar aos jogadores os comentários pertinentes à melhoria de sua expressão, tendo como referência à clareza quanto ao teatro de que se fala.

\footnotetext{
RYNGAERT, Jean-Pierre. Le jeu dramatique en milieu scolaire. Paris: CEDIC, 1977. 175 p.

2 RYNGAERT, 1977.

${ }^{3}$ RYNGAERT, 1977.
} 
Da mesma forma, a noção de distância do ponto de vista brechtiano é fundamental no nosso trabalho, não só para evitar uma abordagem exclusivamente psicológica do fenômeno teatral, mas também para familiarizar os futuros espectadores com as técnicas de jogo contemporâneas ${ }^{4}$.

O analfabetismo teatral e estético, apontado por Richard Monod em suas aulas no Institut d'Etudes Théâtrales e em seus artigos, refere-se, entre outros aspectos, às manifestações teatrais recentes, aos autores dramáticos contemporâneos, aos diretores e ao conceito de direção propriamente dito. Quando não se tem claro de que teatro se fala, é quase sempre comum se ter em mente o teatro burguês, canastrão, bem "arrumadinho", detentor de mensagens bem comportadas, no qual há inexistência de ousadia ou de ruptura. A imagem cultural por ele transmitida, entretanto, não pode ser confundida com o Teatro, na medida em que não passa de uma das concepções as mais comuns de uma forma de teatro. A contemporaneidade no teatro, se tomada como ponto de referência, pode trazer para o universo da sala de aula a noção de ruptura que lhe cabe e que convém aos alunos tomar conhecimento e dela se apropriar no jogo. Neste sentido, o jogo dramático se define como uma arma diante do mundo. Para reforçar esta idéia, atentemo-nos para o que diz George Snyders:

A escola atual não sente o mínimo escrúpulo em funcionar segundo perspectivas temporais a longo prazo, que só actuam a longo prazo e que esmagam o presente. Isto de dois modos: 'Trabalhem bem para que mais tarde triunfes'. Mas a sua expansão presente, a plenitude da sua existência juvenil, serão realmente objecto de preocupação? E por outro lado, a actualidade tem enorme dificuldade em se introduzir como objeto de estudo: a classe dominante teme-a, prefere guardar silêncio - e falar doutra coisa. Com isto condena todos os alunos à apatia ${ }^{5}$.

O jogo dramático vai tentar caminhos, assim como fez o teatro no século XX, mais particularmente as experiências cênicas e performáticas do teatro, a partir dos anos 1960, em que se opera uma ruptura com o compromisso de reproduzir de forma fiel a realidade. A fragmentação, a coexistência do verbal, da imagem e do som sem prioridade de um sobre o outro, a noção de grupo minimizando, a estrutura hierárquica e a escala de valores, a preocupação com o processo são, dentre outros, novos compromissos estéticos para, em lugar de reproduzir, analisar a realidade. À escuta deste teatro, o jogo dramático estrutura-se e organiza seus conteúdos.

Através do enfoque estético e da adoção de novos compromissos em relação à forma que realize a ruptura com o naturalismo, torna-se possível a aquisição de novos hábitos na prática do jogo capazes de colocar em questão tanto os modelos culturais estandardizados quanto as formas estereotipadas de leitura do real. Uma mudança de qualidade na investigação do mundo passa obrigatoriamente por uma mudança de qualidade no modo de fazê-la. Assim, o jogo dramático determina um comportamento político e uma opção pedagógica.

${ }^{4}$ RYNGAERT, 1977, p. 45.

${ }^{5}$ SNYDERS, Georges. Escola, luta e luta de classes. Lisboa: Moraes Editores, 1981. p. 395. 
Os bons sentimentos podem tirar suas vantagens num jogo que fala do racismo de forma geral e bombardeado de clichês. Mas o jogo só oferece real interesse quando ela fala do racismo através da experiência que os jogadores têm, com as dúvidas, as contradições, as interrogações (e também a imaginação) que lhes pertencem. O jogo torna-se produtivo na medida em que ele é preciso, que deixa falar as subjetividades e que leva em consideração os desejos profundos dos participantes. O que é em princípio uma condição indispensável para que haja prazer ${ }^{6}$.

A garantia do jogo ser produtivo passa por esta concepção de engajamento e investimento pessoal determinada pelo jogar a partir de seus próprios interesses. $\mathrm{O}$ que se coloca em jogo são situações que, enfocadas sob expressiva oscilação de seu significado, polemizando-se a partir de diferentes pontos de vista, podem ser trabalhadas esteticamente através das senhas de jogo, dadas pelo animador, que ajudam a dizer, a melhor dizer. Segundo Ryngaert, as senhas vão favorecer a "ginástica do imaginário", quando formuladas levando em consideração, por exemplo, o acaso e o aleatório:

A situação a mais banal, recolocada num espaço previsto, adquire às vezes uma cor nova. A confrontação insólita de personagens não esperados com antecedência permite renovar o estoque de invenções dos participantes, de trazer um pouco de fantasia a um imaginário limitado ou fechado nas convenções ${ }^{7}$.

O mágico, o não-lógico, não só é permitido como através dele se pode chegar a projetar sobre o real um novo olhar, rompendo com a "bem rígida mímesis que eles procuram em vão reencontrar através das vias convencionais". Provocando constantemente o aumento da capacidade de jogo, deixa-se ao jogador a decisão de assumir ou não os riscos, garante-se a autonomia dos grupos e dos indivíduos. Através do vai-e-vem do jogo ao seu questionamento pelos observadores ativos, o processo pedagógico avança em ritmo próprio.

A referência que se quer ao teatro contemporâneo é a fonte para instrumentalizar o professor e ajudar o aluno a dizer, a comunicar de outra forma:

Um contato sólido com o teatro contemporâneo é indispensável, a fim de que os jogadores construam para si pontos de referência, quiçá modelos contraditórios. Ler/ escrever é uma dupla que faz parte da aprendizagem do francês. Jogar/olhar deveria ser uma dupla também natural, as experiências do espectador retroalimentando aquelas do jogador, e vice-versa. A dupla experiência se impõe para que sejam extrapolados os exemplos simplistas de sketches impostos pela televisão, para que seja possível ousar confrontar-se às formas contemporâneas de escrita e de jogo. Uma real relação ao teatro parece-me indispensável ao professor ${ }^{8}$.

\footnotetext{
${ }^{6}$ RYNGAERT, Jean-Pierre. Le jeu dramatique en milieu scolaire (anexe). In QUATRE articles sur art, créativité, expression et jeux dramatiques mis en relation avec ces pratiques. Paris: Institut d’Etudes Théâtrales, Sorbonne Nouvelle, 1984. p. 32. Traduzido por Renan Tavares. Relatório de pesquisa: anexo artigos traduzidos. CNPQ, 1990.

7 RYNGAERT, 1984, p. 33.

8 RYNGAERT, Jean-Pierre. Jouer, représenter. Paris: CEDIC, 1985. p. 40.
} 
A intervenção do professor é bastante delicada, há riscos de manipulação, de omissão, de dirigismo. A atividade pedagógica do professor difere daquela do diretor de teatro, ainda que ambos se preocupem com a teatralidade e com a pesquisa sistemática nos códigos culturais de seus elementos para a construção de produtos - jogos ou espetáculos.

$\mathrm{Na}$ escola, não cabe trabalhar a diversidade de interpretação com relação direta às diversas formações de ator, nem a aquisição de alguns elementos de códigos de jogo e relação à história da arte. O jogo da farsa, da commedia dell'arte, do palhaço, assim como o jogo interessado em elementos de outra cultura, a oriental, por exemplo, não podem ser apreendidos no tempo restrito da programação curricular. Da mesma forma, evita-se entender o jogo teatral, como comumente se faz, como o alargamento do gesto e seu exagero, o tratamento grosseiro que se dá ao traço.

Meus objetivos, mais modestos, orientam-se para a tomada de consciência do que funda o teatro enquanto tal, independentemente do texto e do diálogo. A identificação de alguns sistemas de convenções já é uma etapa satisfatória, que pode ser atingida no interior do jogo, através de algumas "bricolagens artísticas". Elas não conduzem à mestria absoluta das convenções, mas permitem a consciência de sua existência9.

O trabalho pedagógico em relação à teatralidade também não se define pela separação entre forma e conteúdo. Não se trata nem de realizar uma teatralização vazia de sentido, nem de utilizar um código como conjunto de truques só para embelezar uma idéia. A pesquisa de um código acompanha a elaboração do discurso, num mesmo movimento e determinadas pela mesma necessidade.

Segundo Ryngaert, a tomada de consciência dos diversos códigos se realiza pela opção jogo/não-jogo. A aprendizagem de regras simples que marcam a passagem do estado de disponibilidade ao estado de jogo significa o questionamento da transparência em teatro. Ela remete a não mais fazer a diferença entre a pessoa e a personagem, a falar dela como se fosse verdade, a falar do jogo como se tratasse do mundo. $O$ jogo inscrito num sistema determinado se realiza como reconhecimento da "mentira". A aprendizagem desta passagem do não-jogo ao jogo assinala a existência das convenções e que a seleção de uma delas é necessária para "mentir verdadeiramente".

$\mathrm{Na}$ medida em que a teatralização não é encarada como um molde para vestir um significado a priori estabelecido, o jogo dramático procura se realizar a partir de senhas concretas que provoquem a teatralidade no momento da produção dos signos. São elas que relativizam a anterioridade ou posteridade da forma em relação ao conteúdo e vice-versa.

Todas estas senhas trabalham sobre a materialidade do jogo e, em primeiro lugar, as senhas espaciais que impõem convenções rigorosas. Limitar-me-ei ao exemplo de jogadores que devem considerar o espaço imposto, que não corresponde ao lugar real, onde se desenvolve a situação que escolheram. Tomando consciência da metáfora espacial, descobrem também que a teatralização não se limita ao exagero ou ao efeito.

$\overline{9}$ RYNGAERT, 1985, p. 58. 
Ela começa com a derrapagem, o deslocamento do sentido, a metáfora. Quando as senhas provocam estas derrapagens, elas caminham na direção de uma teatralização que brota do coração da invençãa ${ }^{10}$.

O autor acrescenta ainda que a teatralidade deve ser identificada no jogo, nascida involuntariamente do lugar real, das atitudes sem jeito dos jogadores, de um efeito de luz fortuito, de uma situação ligeiramente insólita. Uma teatralidade do cotidiano que independe de artifícios, de palco. Trata-se de uma educação do olhar que trabalha sobre a observação do jogo em relação ao ambiente em que se realiza. "A teatralidade do espaço não começa no teatro, assim como a do gesto ou da mímica, ela intervém no cotidiano" $"$.

A solidariedade, que se reivindica ao realizar o jogo dramático entre jogadores e observadores, explicita uma atividade estético-pedagógica que faz interagir dialeticamente: a realidade cotidiana e a criação estética, a inventividade em sala de aula e os processos criativos na arte. Assim, ela não exclui a pressão que o grupo, o coletivo de alunos, possa fazer no sentido de avanços reais. Esta pressão se traduz por uma demanda explícita de fazer a cultura escolar manter uma relação com os problemas da vida. A cultura passa a ser um meio de ação sobre o real e de modificação: não mais se revela na escola através de evasivas, gratuidades nem simplesmente se restringe a exercícios puramente formais.

A educação estética poderia contribuir para a construção de uma escola progressista se ela realmente der conta da desmistificação do ilusório e da mentira que uma determinada classe social atribui à estética adequada e aos produtos difusores de sua ideologia.

Quanto mais obras-primas se conhecerem, mais o peso da verdade e da realidade se sobreporá ao artificial burguês. As exigências dos alunos proletários, tomadas em conta e interpretadas por professores progressistas, correspondem à passagem da classe de André Theuriet a Eluard. A cultura operária carece da escola não para se renegar, mas para se realizar. A escola precisa de que a pressão operária seja forte: de outro modo corre o risco de se esquecer de tirar das obras culturais sua substância revolucionária ${ }^{12}$.

No segundo momento, propomo-nos a, através de duas reflexões com base nas idéias de Ryngaert, interrogar nossa prática pedagógica no Ensino Fundamental e Médio, nos quais o jogo marca presença cotidianamente.

Em primeiro lugar, vamos tratar de sua desconfiança em relação aos "exercícios” e à transmissão simplista de técnicas de interpretação para o ator. Mesmo sabendo como é difícil para a maioria dos grupos se lançar de imediato em um trabalho aprofundado, sem esta espécie de "aquecimento", ou "tempo de relacionamento", ou ainda "limpeza do espaço", lembra-nos que os jogos e exercícios difundidos por Augusto Boal, entre outros existentes, retirados de seu contexto, de sua significação ideológica (como no caso do Teatro do Oprimido), correm o risco de

${ }^{10}$ RYNGAERT, 1985, p. 60.

${ }^{11}$ RYNGAERT, 1985.

12 SNYDERS, 1981, p. 403. 
se reduzirem a momentos superficiais, mecânicos. Sua desconfiança no tocante aos exercícios se faz acompanhar do desejo de abrir polêmica contra o "não importa o quê" proposto aos alunos, simplesmente porque havíamos feito ou teríamos visto fazer em algum lugar. É necessário ser mais prudente neste sentido. É necessário refletir sobre os objetivos da expressão dramática no meio escolar antes de decidir sobre a escolha destas "entradas" - propostas ou impostas - antes do jogo dramático propriamente dito. Elas podem se dar por elas mesmas.

Sem dúvida alguma, é necessário colocar os indivíduos e os grupos em relação, mas que seja permitido o direito à utopia. Pois estas formas de criar condições para o jogo são inevitavelmente dirigidas por um emissor único (o animador/o professor), que decide no lugar dos participantes o estado que eles devem atingir para produzir "bons jogos". E se os indivíduos tivessem direito a estados diferentes? Ou ainda, se fosse o caso de, ao final do caminho, serem capazes, por eles mesmos, de chegar como bem entendessem a este estado? Para Jean-Pierre Ryngaert, a autonomia dos indivíduos e dos grupos permanece o objetivo maior de seu trabalho. Neste sentido, ele preconiza que estas seqüências iniciais ou "entradas" não se caracterizem como bengalas (a aprendizagem de truques desgastados, ou o esconde-esconde da imaginação) de propriedade única do professor/animador.

Em segundo lugar, acredito ser interessante trazer à tona algumas reflexões de Jean-Pierre Ryngaert sobre seu insistente interesse em “jogar o mundo”, fortemente presente em seu primeiro livro, O Jogo dramático no meio escolar, de 1977. Apesar de ser mal compreendido, como, por exemplo, a necessidade de provar no jogo uma boa vontade ideológica um pouco inocente ou uma certeza política qualquer, o jogo dramático, correndo o risco de ser ou não didático, não escaparia dos "grandes temas" - quer renovados pela moda ou pela necessidade: a poluição, a violência, a miséria, a família, as drogas, a mídia. Ryngaert nos revela que, ao propor aos jogadores de se investir pessoalmente no jogo, como uma alternativa, corre-se o risco de sermos considerados suspeitos de favorecer o olhar voltado para seu próprio umbigo, a confissão íntima ou o psicodrama pirateado.

É bem verdade que o que os participantes jogam não apresenta interesse algum (nem para eles, nem para os outros), a não ser quando coloca em questão uma imagem do mundo que lhes diz respeito diretamente, em que eles podem se incluir. O jogo dramático, assim, torna-se produtivo, pois deixa falar as individualidades e leva em consideração o desejo profundo dos jogadores. Torna-se, assim, fonte de prazer.

O prazer reside também no interesse que cada um adquire em jogar o que lhe atrai e a fazer comungar seus interesses. Ryngaert nos lembra que é preciso nos encorajar a ter paciência, quando as situações abordadas não nos agradam pessoalmente. Por que diabos um grupo ou indivíduos aceitariam, da noite para o dia, lançar sobre a área de jogo preocupações que lhes pertencem ou às vezes lhes questionam? Por que estas preocupações seriam expostas diante dos outros, do professor/animador, nos quais eles, em princípio, não vêem razão para depositar confiança? Em nome do quê este professor/animador decidiria bem rapidamente o que é importante e o que não o é? As situações impostas ou caídas de pára-quedas não se revelam produtivas; são as senhas que ajudam a dizer, afirma Ryngaert. 
No sentido de trazer mais clareza a esta reflexão, vejamos o exemplo que ele nos dá com uma turma de $2^{a}$. Série do Ensino Médio: foi proposto se trabalhar em torno de Mãos Sujas, de Jean-Paul Sartre, peça estudada em sala de aula de literatura. Os adolescentes decidiram jogar as cenas não escritas, simplesmente mencionadas no texto de Sartre, as quais tinham uma relação com a infância ou a adolescência do personagem Hugo. A máscara do personagem serviu para que eles falassem daquilo que lhes dizia respeito: situações imediatas que eles tinham dificuldade de ver claramente, que os confrontavam com suas próprias famílias. O jogo encontra uma formidável alegria, quando introduz no aqui e agora imagens concretas de um algum lugar que diz respeito diretamente aos jogadores, reafirma Ryngaert. Assim, duas jovens da Martinica, recém-chegadas no Liceu de um subúrbio de Paris, jogam com delícia e um certo alívio, uma cena em que camponeses de seu país chegam em casa ao final de uma jornada de trabalho. Falando em crioulo aos personagens turistas e se movimentando de forma que ninguém da turma jamais as viu se movimentar, elas afirmam, com uma força tranqüila, uma identidade que elas não tinham ainda podido (ou querido) assumir no espaço escolar. Ryngaert acrescenta ainda que num momento posterior ao jogo, as jovens o resumiram como o desejo de jogar "lá", fazendo este "lá" entrar na turma simplesmente porque lhes dizia respeito, porque elas se incluíam na imagem do mundo que apresentavam e da qual se apropriaram ao jogá-la.

Sendo assim, ele volta a nos falar da paciência, pois, às vezes, são necessários dez jogos sobre situações desgastadas ou falsamente imitadas para que nasça uma imagem forte. Aprender a dizer leva tempo, mas, segundo Ryngaert, este tempo nunca é inutilmente perdido.

\section{Concluindo}

O jogo dramático na educação prioriza colocar em tensão o jogo espontâneo e aquele regido por códigos teatrais. Não se trata de negar a "livre expressão", mas de provocá-la em relação às formas e estruturas nas quais se realizam as inúmeras possibilidades da representação teatral. A provocação visa o deslocamento da livre-expressão para um encaminhamento lúcido, ainda que de experimentação das formas de representação da arte teatral, da apropriação das possibilidades expressivas realizáveis segundo códigos precisos. Do ponto de vista pedagógico, há que ser não-diretivo e saber respeitar o direito do aluno à sua autonomia e à sua opção pelos riscos que quer assumir no jogo.

Quando Jean-Pierre Ryngaert coloca em questão as longas séries de jogos ou exercícios que precedem o jogo dramático (comum a muitas práticas), ele, ao mesmo tempo, elabora a crítica à manutenção do espontaneísmo no jogo que, em geral, esta fase preparatória opera. $\mathrm{O}$ comportamento lúcido e autônomo que se espera do aluno entra em tensão como o que se entende ser espontâneo, natural, próprio, livre. $\mathrm{Na}$ nossa prática pedagógica, percebemos em crianças, adolescentes e adultos uma reduplicação de modelos culturais, do "déjà vu" que colocam radicalmente em questão a possibilidade de se entender o jogo espontâneo como expressão inocente, imaculada, não adulterada.

O comportamento lúcido passa por uma apropriação da expressão estética, 
colocando em questão os inevitáveis estereótipos que acompanham qualquer manifestação de livre expressão. A viabilidade deste comportamento lúcido só pode ser garantida pela relação que o jogo dramático estabelece com a estética teatral.

Os professores de arte deveriam de fato mostrar a seus alunos que o inconsciente não deve ser reprimido, que ele pode tornar-se a fonte de uma grande vitalidade [...] mas somente quando dominado pelas forças do ego e enriquecido por ele. O que é necessário é um trabalho disciplinado do material inconsciente caótico; é necessário que ele seja transformado e moldado em formas que sejam significativas tanto para o artista quanto para os outros. Nossos alunos deveriam aprender que o inconsciente, quando utilizado como uma fonte natural, pode enormemente dar vida ao conjunto da personalidade; enquanto que a expressão livre e desenfreada do inconsciente é um passo em direção à desintegração da personalidade ${ }^{13}$.

Bruno Bettelheim acrescenta à preocupação com o espontaneísmo, ao fazer não importa o quê, ao não ter nenhuma postura crítica face à reprodução de modelos culturais, os riscos da livre-expressão desenfreada, inconsciente, na educação. Chama a atenção dos professores sobre o fato de que os riscos podem ser evitados, ao levar em conta o trabalho lúcido do artista, da arte, como referência central e prioritária para um trabalho de educação estética.

Não se pode esquecer da importância da relação entre jogadores e observadores no jogo dramático no sentido de determinar os avanços do grupo e de cada indivíduo no tocante à lucidez e à autonomia. Não cabe ao professor nem acelerar, nem atrasar o processo que o grupo desenvolve, mas saber usar de paciência para evitar diretividade neste processo. A referência à arte, de forma constante e oportuna, é uma garantia para uma pedagogia não-diretiva, para o aumento gradativo da capacidade de jogo dos estudantes e não devemos jamais nos esquecer de que o produto artístico é polissêmico, abre possibilidades de caminhos, opções e recusas. $\mathrm{O}$ que, sem dúvida, favorece uma educação estética associada à "tomada de consciência criadora do mundo de hoje".

${ }^{13}$ BETTELHEIM, Bruno. Pontos de vista pessoais sobre a arte e a educação artística. In: QUA$T R E$ articles sur art, créativité, expression et jeux dramatiques mis en relation avec ces pratiques. Paris: Institut d'Etudes Théâtrales, Sorbonne Nouvelle, 1984. p. 3. 


\section{REFERÊNCIAS}

BETTELHEIM, Bruno. Pontos de vista pessoais sobre a arte e a educação artística. In: QUATRE articles sur art, créativité, expression et jeux dramatiques mis en relation avec ces pratiques. Paris: Institut d'Etudes Théâtrales, Sorbonne Nouvelle, 1984.

RYNGAERT, Jean-Pierre. Le jeu dramatique en milieu scolaire. Paris: CEDIC, 1977.

RYNGAERT, Jean-Pierre. Le jeu dramatique en milieu scolaire (anexe). In QUATRE articles sur art, créativité, expression et jeux dramatiques mis en relation avec ces pratiques. Paris: Institut d'Etudes Théâtrales, Sorbonne Nouvelle, 1984. p. 31-35. Traduzido por Renan Tavares. Relatório de pesquisa: anexo artigos traduzidos. CNPQ, 1990.

RYNGAERT, Jean-Pierre. Jouer, représenter. Paris: CEDIC, 1985.

SNYDERS, Georges. Escola, luta e luta de classes. Lisboa: Moraes Editores, 1981. 